\title{
Recommendations for Metabolic and Bariatric Surgery During the COVID-19 Pandemic from IFSO
}

\author{
Wah Yang ${ }^{1} \cdot$ Cunchuan Wang $^{1} \cdot$ Scott Shikora ${ }^{2} \cdot$ Lilian Kow $^{3}$ \\ Published online: 14 April 2020 \\ (C) Springer Science+Business Media, LLC, part of Springer Nature 2020
}

\section{Background}

Coronavirus disease 2019 (COVID-19) emerged in Wuhan City and rapidly spread throughout China and around the world since December 2019 [1]. The World Health Organization (WHO) declared the COVID-19 outbreak a global pandemic on 11 March 2020 [2, 3].

Patients with metabolic disorders like cardiovascular diseases, diabetes and obesity may face a greater risk of infection of COVID-19 and it can also greatly affect the development and prognosis of pneumonia [1, 4-6].

In response to the COVID-19 pandemic outbreak, the International Federation for the Surgery of Obesity and Metabolic Disorders (IFSO) has issued these recommendations to our global healthcare providers aimed at keeping all our patients and practice staff in an as safe an environment as possible.

Wah Yang is President-elect of Young IFSO

Cunchuan Wang is President-elect of IFSO-APC

Scott Shikora is President-elect of IFSO

Lilian Kow is President of IFSO

Cunchuan Wang

twcc@jnu.edu.cn

Scott Shikora

sshikora@bwh.harvard.edu

$\checkmark$ Lilian Kow

lilian.kow@flinders.edu.au

1 Department of Metabolic and Bariatric Surgery, The First Affiliated Hospital, Jinan University, Guangzhou, China

2 Brigham and Women's Hospital, Harvard Medical School, Boston, MA, USA

3 Adelaide Bariatric Centre, Flinders Private Hospital, Bedford Park, Adelaide, South Australia, Australia

\section{General Recommendations}

All elective surgical and endoscopic cases for metabolic and bariatric surgery should be postponed during the pandemic. This minimises risks to both patient and healthcare team, as well as reducing the utilisation of unnecessary resources, such as beds, ventilators and personal protective equipment (PPE). In addition, postponing these services will minimise potential exposure of the COVID-19 virus to unsuspecting healthcare providers and patients [7].

\section{Screening and Diagnosis}

The body temperature of all patients upon arrival at endoscopy units, clinics or inpatient wards should be checked and documented. All admissions to hospital should be screened for COVID-19 by chest computed tomography (CT) scan and be confirmed by real-time reverse-transcriptase polymerase chain reaction (RT-PCR) assay for nasal and pharyngeal swab specimens [8-11]. COVID-19 should be diagnosed on the basis of the WHO interim guidance [12]. Isolation precautions should be taken for those awaiting test results.

All patients should be asked about recent history of fever or respiratory symptoms, family members or close contacts with similar symptoms, any contact with a confirmed case of COVID-19 and recent travel to high-risk areas.

\section{Emergency Surgery for Treating Postoperative Complications}

Only emergency surgeries for treating severe complications of bariatric surgery are recommended during the COVID-19 pandemic, for example postoperative bleeding, leak, etc. However, differential diagnosis should be made as similar clinical characteristics such as fever or respiratory symptoms can be present in both COVID-19 
patients and patients with postoperative leak, infection or bleeding. Multidisciplinary team should work together for these cases.

\section{Suspected or Confirmed COVID-19 Cases}

For any suspected or confirmed COVID-19 cases during the pandemic, emergency surgery can be offered after considering conservative treatment. The surgery should be performed in negative pressure rooms and isolation precautions should be taken.

All staff in the facility including surgeons, nurses and anaesthesiologists shall carry out high level of precautions with protective equipment: disposable surgical cap, medical protective mask (N95), disposable medical protective uniform, disposable latex gloves, full-face respiratory protective devices or powered air-purifying respirator.

The number of surgical participants should be reduced. The operation should be performed by a well-coordinated surgical team to minimise the operation time. Proper prevention and management measures should be embedded during laparoscopic surgery to lower the risk of aerosol exposure for the operation team. Operating rooms and equipment should be sterilised separately and thoroughly and should pass the evaluation by the infection management authorities before next use.

\section{Patients Recovered from COVID-19}

As the long-term effects or complications of COVID-19 are still unknown, metabolic and bariatric surgeries for patients who were diagnosed and recovered from COVID-19 should be evaluated by a multidisciplinary team. Diet and lifestyle modifications should be advised before surgical treatment.

\section{Follow-up and Integrated Health Allied Support}

Clinic and hospital visits are not recommended. Telemedicine, online or phone follow-up should be considered if possible, in order to decrease the hospital density of patients, and provide the much-needed care to patients who are less willing or unable to travel.

Integrated health allied support especially nutritional and psychological advice should be provided during difficult times. Some patients have limited sources of food and are in considerable fear of the crisis in quarantined areas.

\section{Academic Activities and Conferences}

All face-to-face academic activities and conferences should be cancelled or postponed. Online and virtual conference will be a good option.

\section{General Public with Obesity and Metabolic Disorders}

Regular treatment for metabolic disorders such as cardiovascular diseases and diabetes should be enhanced. Healthy diet and proper physical activities to improve self-immunity should be advocated. Timely assessment and treatment should be advised if signs and symptoms of COVID-19 appeared.

Everyone must practise good hygiene to protect against infection and prevent the virus spreading. Good hygiene includes:

- Covering your coughs and sneezes with your elbow or a tissue

- Disposing of tissues properly

- Washing your hands often with soap and water, including before and after eating and after going to the toilet

- Using alcohol-based hand sanitisers

- Cleaning and disinfecting surfaces

- If you are sick, avoiding contact with others and staying more than $1.5 \mathrm{~m}$ away from people

- Cleaning and sanitising frequently used objects such as mobiles, keys and wallets

Surgical masks in the community are helpful in preventing people who have coronavirus disease from spreading it to others. If you are well, you do not need to wear a surgical mask. There is little evidence that widespread use of surgical masks in healthy people prevents transmission in public (from Australian Government Department Health Website: https://www.health.gov.au/ news/health-alerts/novel-coronavirus-2019-ncov-healthalert/what-you-need-to-know-about-coronavirus-covid19\#protect-yourself-and-others).

\section{Preparation for Returning to Normal Clinical Practice}

All routine surgeries should be rescheduled until after the pandemic is over. Public education can be offered via online websites, mobile phone apps and other virtual means during the pandemic crisis. Pre-operative preparation can be advised for candidates of the surgery.

If surgery is considered, screening and precaution measures should be taken strictly just like during the 
pandemic. Safety of the patients and healthcare staff is the first priority in all clinical practices. Number of surgeries should be controlled on a limited basis. We should also follow the regulations and laws set up by the local authorities during this special period of time.

\section{Further Updated Reading Resources}

The Chinese Center for Disease Control and Prevention (CDC) has published a critical multilingual manual in both English and French to share the most up-to-date COVID-19 control and prevention information with other countries [13]: China CDC (webpage: http://en.nhc.gov.cn/2020-03/03/c 77246.htm). The CDC of the USA and other countries also have the latest COVID-19 information on their websites.

\section{Conclusions}

IFSO has an obligation to help contain and mitigate the effects of the pandemic on the global scientific, surgical and integrated health communities and protect the health of all IFSO members and their families and all those associated with our members at work, at home and in the community. We plan to work together and provide updates as appropriate.

\section{Compliance with Ethical Standards}

Conflict of Interest All authors declare that they have no conflict of interest. However, Scott Shikora is the Editor-in-Chief of Obesity Surgery.

\section{References}

1. Guan WJ, Ni ZY, Hu Y, et al. Clinical characteristics of coronavirus disease 2019 in China. N Engl J Med. 2020 Feb;28 Epub 2020/02/ 29. eng
2. WHO characterizes COVID-19 as a pandemic. [11 March 2020]; Available from: https://www.who.int/emergencies/diseases/novelcoronavirus-2019/events-as-they-happen.

3. WHO Director-General's opening remarks at the media briefing on COVID-19 - 11 March 2020. [23 March 2020]; Available from: https:/www.who.int/dg/speeches/detail/who-director-general-sopening-remarks-at-the-media-briefing-on-covid-19\%2D\%2D-11march-2020.

4. Li B, Yang J, Zhao F, et al. Prevalence and impact of cardiovascular metabolic diseases on COVID-19 in China. Clin Res Cardiol. 2020 Mar;11 Epub 2020/03/13. eng

5. Wang D, Hu B, Hu C, Zhu F, Liu X, Zhang J, et al. Clinical characteristics of 138 hospitalized patients with 2019 novel coronavirus-infected pneumonia in Wuhan, China. Jama. 2020 Feb 7. Pubmed Central PMCID: PMC7042881. Epub 2020/02/ 08. eng.

6. Gupta R, Ghosh A, Singh AK, Misra A. Clinical considerations for patients with diabetes in times of COVID-19 epidemic. Diabetes \& Metabolic Syndrome: Clinical Research \& Reviews. 2020 2020/05/ 01/;14(3):211-2.

7. JOINT GI SOCIETY MESSAGE: COVID-19 clinical insights for our community of gastroenterologists and gastroenterology care providers. [23 March, 2020]; Available from: https://www.asge. org/home/joint-gi-society-message-covid-19.

8. Zu ZY, Jiang MD, Xu PP, Chen W, Ni QQ, Lu GM, et al. Coronavirus disease 2019 (COVID-19): a perspective from China. Radiology.0(0):200490.

9. Huang C, Wang Y, Li X, et al. Clinical features of patients infected with 2019 novel coronavirus in Wuhan, China. Lancet. 2020 Feb 15;395(10223):497-506. Epub 2020/01/28

10. Li Y, Xia L. Coronavirus disease 2019 (COVID-19): role of chest CT in diagnosis and management. Am J Roentgenol 2020:1-7.

11. Ai T, Yang Z, Hou H, et al. Correlation of chest CT and RT-PCR testing in coronavirus disease 2019 (COVID-19) in China: a report of 1014 cases. Radiology. 2020 Feb;26:200642. Epub 2020/02/27. eng

12. Clinical management of severe acute respiratory infection when novel coronavirus (2019-nCoV) infection is suspected: interim guidance. [January 28, 2020]; Available from: https://www.who. int/docs/default-source/coronaviruse/clinical-management-ofnovel-cov.pdf.

13. China CDC: Multilingual epidemic control manuals for COVID19. [23 March 2020]; Available from: http://en.nhc.gov.cn/202003/03/c_77246.htm.

Publisher's Note Springer Nature remains neutral with regard to jurisdictional claims in published maps and institutional affiliations. 